\title{
Implementasi SMART LIBRARY menggunakan konsep inernet of thing dalam meningkatkan pelayanan perpustakaan
}

\author{
Muhammad Khoir Al Alim Manurung
}

\begin{abstract}
This paper discusses how the library is transformed and develops along with the development of the times in order to compete with things that rival the library, such as ebooks and books by utilizing other technologies. In educating the life of the nation, especially students as academic people as well as iron stock for the civilization of the nation and state, the existence of a library is a basic thing that must be considered, and of course must be integrated with technological developments to provide ease of service to users and can maximize library services and of course will increase the attractiveness of the library itself. The evolution of library services today has evolved digitally, but with increasingly rapid and instant technological developments so that digitalized library services are still considered to be less effective and less efficient in time and costs. Therefore, the author offers an idea namely Smart library, which is a mobile application-based library information system with the integration of IoT concepts in libraries that can be used by users using their respective smartphones. This paper also contains a system of smart library usage, its ease, obstacles that have been found by the community with the use of manual systems and how to progress when using systems that have been transformed with technology.
\end{abstract}

Seiring dengan perkembangan teknologi dan komunikasi yang semakin canggih dan pesat, hingga arus informasi tanpa batas yang semakin mudah diakses, menjadikan teknologi menjadi sebuah kebutuhan bagi manusia dalam melaksanakan segala aktivitas sehari-hari. Hal ini juga diiringi dengan perubahan zaman yang semakin cepat dan tanpa batas sehingga membawa peradaban dunia pada era revolusi keempat. Pada era ini, segala aktivitas dilakukan dengan cara memanfaatkan eksistensi dari sebuah teknologi, yang mengedepankan proses otomasi dan pertukaran data secara langsung berupa konektivitas antara manusia, mesin dan data yang tercakup didalam Internet of Thing maupun Artificial Intelligence, 
dengan perpaduan antara teknologi robotik maupun sensor dengan memanfaatkan eksistensi internet sebagai penghubungnya. Teknologi informasi dan komunikasi merupakan sebuah tulang punggung pergerakan revolusi keempat ini, hal ini berpengaruh dalam berbagai konsentrasi bidang ilmu pengetahuan manusia tak terkecuali bidang ilmu pengetahuan dan teknologi khususnya bidang pendidikan dan perguruan tinggi. Tantangan ini harus bisa dicermati kemudian direspon oleh semua pemangku kepentingan khususnya di lingkungan akademik. Lingkungan akademik secara umum dikenal oleh khalayak umum dengan literasi pengetahuan dan hasil penelitiannya. Dalam mencapai hal tersebut maka terdapat sebuah proses didalamnya, salah satu proses dalam menangguk literasi pengetahuan tersebut ialah dengan cara bergelut dengan buku.

Aktivitas ini tentu melalui media perpustakaan, perpustakaan merupakan institusi yang mengelola koleksi literasi ilmu pengetahuan hingga penelitian secara unggul dan profesional dengan sistem yang relevan untuk memenuhi kebutuhan informasi untuk pendidikan, penelitian, hingga pelestarian khasanah budaya bangsa. Perpustakaan juga dikenal dengan wadahnya deposit ilmu pengetahuan.

Dalam mencerdaskan kehidupan bangsa khususnya mahasiswa sebagai insan akademis sekaligus sebagai iron stock bagi peradaban bangsa dan negara, eksistensi dari sebuah perpustakaan merupakan hal dasar yang harus diperhatikan, dan tentunya harus diintegrasikan dengan perkembangan teknologi guna memberikan kemudahan pelayanan kepada pemustaka dan dapat memaksimalkan pelayanan perpustakaan dan tentunya akan meningkatkan daya tarik perpustakaan itu sendiri. Evolusi pelayanan perpustakaan dewasa ini telah berkembang secara digitalisasi, akan tetapi dengan perkembangan teknologi yang semakin pesat cepat dan instan sehingga pelayanan perpustakaan yang bersifat digitalisasi masih 
dinilai kurang efektif dan kurang mengefesiensikan waktu dan biaya. Kekurangan dan permasalahan tersebut ialah sebagai berikut :

\section{Kartu anggota perpustakaan kurang efektif dan pemborosan} anggaran.

Kartu anggota perpustakaan merupakan hal yang wajib dibawa pemustaka agar dapat masuk kedalam ruang baca perpustakaan. Apabila pemustaka tidak membawa kartu tersebut maka pemustaka tidak diperbolehkan untuk masuk. Sama juga halnya jika pemustaka lupa untuk membawa kartu anggota perpustakaan tetap tidak diperbolehkan untuk memasuki ruangan, padahal pemustaka tersebut telah terdaftar sebagai anggota perpustakaan, lain halnya apabila pemustaka kehilangan kartu anggota, maka pemustaka mau tidak mau harus mengurusnya kembali agar bisa masuk ke ruang baca perpustakaan tersebut. Ini merupakan hal yang dapat merumitkan pemustaka. Selain itu pengadaan kartu anggota perpustakaan merupakan tindakan pemborosan anggaran, dimana perpustakaan harus menyediakan anggaran untuk keperluan pembelian kartu yang terbuat dari kertas dan plastik, biaya tinta, biaya mesin, perawatan hingga biaya kerusakan apabila mesin rusak sehingga perpustakaan harus menyediakan anggaran yang besar dalam pembuatan kartu anggota.

\section{Pemborosan kertas pada locker penyimpanan barang.}

Keamanan penyimpanan barang di perpustakaan dewasa ini sangat baik yaitu lemari locker berbasis barcode, sehingga tingkat keamanan barang sangat terjamin keamanannya. Pada sistem ini, mesin locker akan secara otomatis memberikan barcode yang dicetak diatas kertas sebagai bukti transaksi, dengan barcode tersebut dapat membuka lemari locker penyimpanan barang. Akan tetapi pada perangkat ini 
boros dalam penggunaan kertas. Penggunaan kertas yang begitu besar dapat menimbulkan dampak bagi lingkungan dan tentunya juga tindakan pemborosan anggaran.

\section{Pencarian buku yang rumit, lama dan bergantung pada komputer.}

Dalam mencari sebuah buku yang diinginkan, pemustaka terlebih dahulu mencari informasi buku melalui komputer, kemudian komputer akan menampilkan informasi mengenai formasi buku beserta kode buku tersebut. Setelah mendapatkan informasi tersebut kemudian pemustaka mencari kembali dengan cara melihat buku satu per satu secara sistematis di lemari buku sesuai dengan informasi yang diperolehnya sebelumnya. Aktivitas ini dapat membantu pemustaka akan tetapi dapat merepotkan pemustaka dalam pencarian buku serta dapat menghabiskan waktu yang cukup lama. Bahkan terkadang pemustaka juga harus antri dengan pemustaka lain untuk mendapatkan hak akses komputer untuk mencari informasi buku yang mereka cari. Selain itu aktivitas pencarian buku hanya bergantung pada komputer, apabila listrik padam atau komputer rusak maka pemustaka akan kehilangan arah dalam mencari buku dan pastinya akan menghabiskan lebih banyak waktu dalam mencari buku yang mereka cari.

\section{Pelayanan dan informasi perpustakaan yang terbatas}

Pelayanan perpustakaan hanya bisa dilakukan pada saat perpustakaan buka, apabila perpustakaan tutup maka segala pelayanan tidak tersedia. Dalam pelayanan peminjaman buku misalnya, apabila batas waktu peminjaman telah habis dan pemustaka ingin melakukan perpanjangan peminjaman buku pada saat itu, maka hal yang harus dilakukan pemustaka ialah datang ke 
bagian pelayanan perpustakaan. Selain itu dalam informasi pencarian buku, pemustaka hanya bisa mendapatkan informasi dan membaca buku pada saat diperpustakaan buka. Seharusnya layanan informasi perpustakaan luas dan tidak terbatas melihat kemajuan teknologi dan informasi yang ada batasnya.

Berdasarkan permasalahan tersebut, maka perpustakaan perlu di revolusi sesuai dengan trend peradaban dunia saat ini yaitu revolusi peradaban keempat. Dengan memanfaatkan eksistensi smartphone dalam pelayanan perpustakaan berbasis IoT (Internet of Thing). Smartphone sendiri telah menjadi bagian yang tidak dapat dipisahkan dari kehidupan manusia. Oleh karenanya perpustakaan perlu diintegrasikan melalui smartphone dengan menggunakan konsep IoT. IoT merupakan konsep dimana semua benda di dunia nyata dapat berkomunikasi dan berbagi informasi antara satu dengan yang lainnya sebagai bagian dari satu kesatuan sistem yang terpadu menggunakan jaringan internet sebagai penghubungnya. Konsep IoT telah berkembang pesat di era revolusi keempat ini. Sehingga penulis menawarkan sebuah ide yaitu Smart library, yang merupakan sebuah sistem informasi pelayanan perpustakaan berbasis mobile application dengan integrasi konsep IoT di perpustakaan yang dapat digunakan oleh pemustaka menggunakan smartphone masing-masing. Sehingga diharapkan mampu meningkatkan pelayanan perpustakaan, mengefesiensikan waktu dan anggaran perpustakaan, serta mengurangi dampak terhadap lingkungan.

Berikut solusi dan konsep implementasi layanan Smart Library

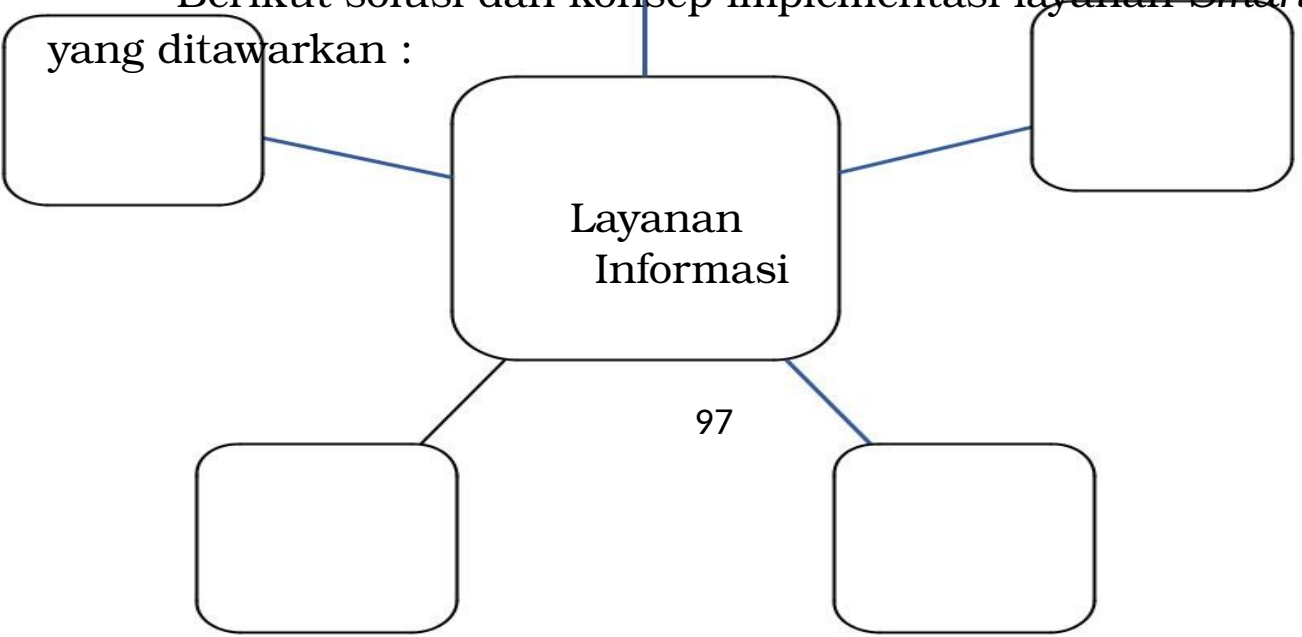




\section{Realtime}

$\begin{array}{lc}\text { Smart } & \text { Sm } \\ \text { Library } & \text { art } \\ & \text { Searc } \\ & \text { hing }\end{array}$

Internet

Global

of Thing

Positionin

$g$

System 
Gambar 1. Konsep Smart Library.

1. Kartu anggota perpustakaan menggunakan fingerprint dan barcode mobile. Pemustaka memiliki satu akun user dan profil yang telah didaftarkan dan telah dikonfirmasi oleh petugas administrasi perpustakaan. Dengan data yang terdiri dari biodata pemustaka, fingerprint, dan barcode hak user. Dalam memasuki perpustakaan pemustaka dapat menempelkan jarinya ke sistem fingerprint yang telah disediakan selain itu juga bisa menggunakan barcode hak user pada akun pemustaka. Selain itu barcode hak user juga bisa digunakan untuk locker penyimpanan barang, dengan cara generate barcode tersebut pada sistem locker penyimpanan barang.

2. Smart searching, aktualisasi IoT dan GPS, integrasi smartphone dan buku. Berdasarkan analisis permasalahan pada layanan perpustakaan sebelumnya, pemustaka mencari buku dengan bantuan komputer kemudian mencarinya kembali di lemari buku perpustakaan. Pada smart library yang diusulkan informasi pencarian buku dapat diakses melalui smartphone pemustaka kapan saja dan dimana saja. Berikut penjelasan konsep smart searching dengan metode IoT antara smartphone dengan buku perpustakaan. Pada konsep smart searching ini seluruh buku telah terdata dalam satu database katalog buku perpustakaan dengan, kemudian smartphone dan buku tersebut saling bertukar informasi satu dengan lainnya 
dengan komunikasi pengenal kode buku tersebut yang terhubung dalam satu layanan konektifitas internet. Pemustaka terlebih dahulu memilih buku yang ingin dicari pada database koleksi buku perpustakaan yang dapat diakses melalui aplikasi smart liibrary kemudian setelah menemukan buku yang diinginkan maka aplikasi tersebut akan menampilkan informasi buku, peta lokasi buku, dan kode buku yag dicari. Setelah itu aplikasi dapat menunjukkan peta, arah lokasi pemustaka dengan lokasi buku yang dicari menggunakan metode GPS (Global Positioning System), yang diintegrasikan dengan CCTV perpustakaan.

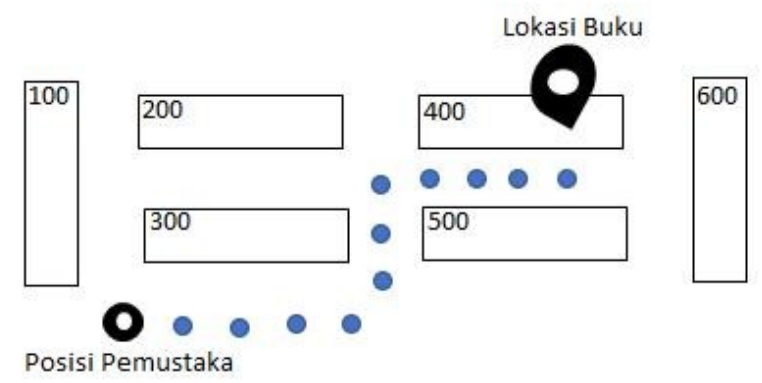

Gambar 2. Peta lokasi buku.

Setelah sampai ditujuan maka pemustaka dapat mengarahkan smartphonenya ke arah sekumpulan buku tersebut. Kemudian smarphone akan mendeteksi kumpulan-kumpulan buku yang telah diidentifikasikan dengan chip pengenal kode buku yang berbeda-beda. Dan apabila chip kode buku tersebut terdeteksi oleh smartphone maka akan sebuah reaksi gelombang sehingga 
chip kode buku akan memberikan sinyal kepada smartphone, sehingga smartphone akan merespon dengan bergetar kemudian memberikan sebuah informasi bahwa buku telah ditemukan.

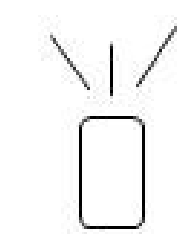

Smartphone

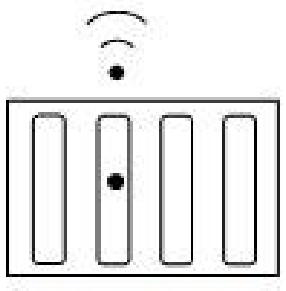

Lemari Buku

Gambar 3. Konsep Smart Searching.

Dengan layanan smart searching dengan konsep IoT ini, maka proses pencarian buku dapat ditemukan dengan mudah, instan dan cepat. Selain itu dapat menghemat anggaran perpustakaan, tanpa harus menyediakan aggaran untuk membeli perangkat komputer, melihat smartphone merupakan suatu hal pokok yang dimiliki oleh semua manusia pada era ini.

3. Layanan dan informasi perpustakaan dapat diakses melalui smartphone.

Informasi data katalog buku dapat diakses melalui aplikasi ini, selain itu juga dapat melakukan perpanjangan peminjaman buku sehingga pemustaka tidak perlu repot harus datang ke perpustakaan untuk melakukan 
perpanjangan peminjaman buku. Dan didalam aplikasi ini juga tersedia notifikasi pengingat kepada pemustaka jangka peminjaman buku.

4. Tersedianya informasi tentang kondisi perpustakaan secara realtime.

Pemustaka terkadang perlu mengetahui kondisi perpustakaan pada saat itu juga tanpa harus masuk kedalam perpustakaan. Dan hal tersebut dapat mempengaruhi pemustaka dalam mengambil keputusan. Informasi tersebut seperti jumlah intensitas pengunjung perpustakaan saat itu, informasi kecepatan koneksi internet, informasi cuaca dan lain sebagainya sehingga pemustaka bisa mengetahui kondisi perpustakaan tanpa harus datang keperpustakaan.Layanan dan informasi perpustakaan dapat diakses melalui smartphone.

Informasi data katalog buku dapat diakses melalui aplikasi ini, selain itu juga dapat melakukan perpanjangan peminjaman buku sehingga pemustaka tidak perlu repot harus datang ke perpustakaan untuk melakukan perpanjangan peminjaman buku. Dan didalam aplikasi ini juga tersedia notifikasi pengingat kepada pemustaka jangka peminjaman buku.

5. Tersedianya informasi tentang kondisi perpustakaan secara realtime.

Pemustaka terkadang perlu mengetahui kondisi perpustakaan pada saat itu juga tanpa harus masuk kedalam perpustakaan. Dan hal tersebut dapat 
mempengaruhi pemustaka dalam mengambil keputusan. Informasi tersebut seperti jumlah intensitas pengunjung perpustakaan saat itu, informasi kecepatan koneksi internet, informasi cuaca dan lain sebagainya sehingga pemustaka bisa mengetahui kondisi perpustakaan tanpa harus datang keperpustakaan.

6. Tersedianya buku elektronik pada seluruh koleksi perpustakaan

Ini akan memudahkan pemustaka dalam menangguk informasi dan literasi ilmu pengetahuan tanpa batas, selain itu juga dapat menghemat anggaran dalam pendistribusian buku. Selain itu juga dapat mendukung proses e-learning di instansi pendidikan. Peradaban perpustakaan yang berliterasi ditandai dengan kepedulian terhadap perpustakaan dengan mengintegrasikan perkembangan dunia dengan kemajuan teknologi. Semakin berkualitas pelayanan perpustakaan maka semakin berkualitas pula sumber daya yang akan dihasilkan. Revolusi perpustakaan dengan kemajuan teknologi penting agar perpustakaan tidak dinilai sebagai institusi yang ketinggalan zaman dan membosankan. Akan tetapi dengan eksistensi dari perpustakaan tersebut dapat mencerminan kemajuan dan merefleksikan kehidupan budaya akademis. Maka dengan revolusi perkembangan perpustakaan diharapkan mampu mengkorelasikan perubahan zaman dengan budaya masyarakat saat ini, sehingga dapat mendongkrak kualitas pelayanan perpustakaan selain. 
Perpustakaan merupakan media. Perpustakaan dalam bentuk mobile application yaitu smart library menjadi sebuah representasi perkembangan teknologi informasi dan komunikasi di perpustakaan untuk meningkatkan kualitas pelayanan perpustakaan. Smart library mempunyai ciri dan kelebihan yaitu sebagai berikut :

Smart library berbasis mobile application yang dapat diakses melalui smartphone sehingga mudah dibawa kemanapun dan kapanpun, selanjutnya aksesibilitas yang tinggi artinya kemudahan terhadap pengaksesan informasi layanan perpustakaan. Misalnya dalam mengakses informasi buku dapat dilakukan melalui smartphone tanpa harus ke perpustakaan karena akses tersedia secara global dan mudah.

Dengan smart library, penggunaan kertas akan menurun drastis (paperless). Dimana kertas tidak diperlukan dalam proses pelayanan melainkan pelayanan lebih bersifat virtual dengan memanfaatkan smartphone. Dengan begitu maka pelayanan perpustakaan akan lebih ramah terhadap lingkungan dengan cara meminimalkan penggunaan kertas pada sistem locker penyimpanan barang dengan sistem bantuan barcode dalam smartphone.

Selain itu dengan smart library dapat mendukung proses pembelajaran online e-learning di instansi pemerintahan dan dapat membaca buku yang diinginkan tanpa harus bergantung pada tempat dan waktu buka perpustakaan. Denagn e-book juga dapat mengurangi anggaran pendistribusian koleksi buku perpustakaan Pelayananan perpustakaan juga lebih cepat, 
misalnya dalam proses pencarian buku dengan menggunakan konsep IoT (Internet of Thing). Tanpa harus menggunakan sumber daya komputer dalam proses pencariannya melainkan menggunakan smartphone pemustaka masing-masing. Dan juga dapat meningkatkanan produktivitas pemustaka dalam mendapatkan informasi semakin tinggi karena koleksi e-book, jurnal dan lain sebagainya dapat dilihat melalui smartphone. Sehingga akan terbentuk budaya masyarakat yang berlandaskan pada literasi dan ilmu pengetahuan.

Dengan adanya smart library yang berpedoman pada prinsip accessability, usability, sustainablity, diharapkan mampu menjawab tantangan dunia di era revolusi keempat ini guna meningkatkan pelayanan perpustakaan kearah yang lebih baik.

\section{Daftar Pustaka}

Abid, Nuskhan. "Peluang Dan Tantangan Pelayanan Perpustakaan Berbasis Media Sosial: Perspektif Pustakawan Stain Kudus”. Libraria. Vol. 5, No. 1. (Juni 2017)

Fatmawati, Endang. "Pemanfaatan Aplikasi Perpustakaan Digital Ijateng Melalui Smartphone." Profetik jurnal komunikas., Vol.10. No.02. (2017).

Hidayat, Rahmat. dan Reza Setiawan. "Perancangan Aplikasi Pemetaan Sarana Olahraga (PSO) Berbasis Website dan Selular Sebagai Informasi untuk Memetakan Sarana Olahraga". Jurnal Edukasi dan Penelitian Informatika. Vol. 3, No. 1, (2017).

Istiana, Purwani. 2014. Layanan Perpustakaan. Yogyakarta:

Ombak. 